\title{
Steps of Designing a Personal Questions Bank in a Pedagogical Way
}

\author{
Mona M. Hamad \\ Department of English, College of Science \& Arts for Girls, Muhayil, King Khalid University, Abha, Saudi Arabia \\ Ehab S. Alnuzaili \\ Department of English, College of Science \& Arts for Boys, Muhayil, King Khalid University, Abha, Saudi Arabia
}

\begin{abstract}
Teaching is one of the most important professions that affect different aspects of life. Despite the difference between teaching and testing process, they have a huge interdependent and integrated relation. Teasing information out of them is a complicated process when they are separated. The educational objectives can't be achieved without the integration between teaching and testing .This paper addresses steps of designing a questions bank that may help teachers come out with perfect tests that evaluate different levels of Bloom's Taxonomy cognitive domain, backwash the whole process of the course learning, and reflect intended learning outcomes (ILOs). This paper helps teachers design their questions bank while they are teaching and illustrates steps of feeding it with different types of questions using the cognitive domain of Bloom's Taxonomy, table of specification (TOS) and level of difficulties in a pedagogical way.
\end{abstract}

Index Terms-Questions bank, pedagogical, intended learning outcomes (ILOs), table of specification (TOS)

\section{INTRODUCTION}

Teaching process can't be developed without testing. Testing helps educators to carry on teaching and to evaluate their success of achieving a course objective, so their integration is a must. Popham (2003) points out that teaching and testing are related to each other: when teachers teach instructionally, students perform better, and critical connection between one's teaching and one's testing, substantial increase in instructional effectiveness, depends on understanding this connection properly. Brown (1994) pointed that despite the difference between testing and teaching, they are connected to each other in an interwoven way that they cannot be separated. Popham (2003) defines an educational test as a formal way to determine students' status of knowledge skills and attitudes. Teachers teach their students a whole course, then test them to find out if they have reached their goal or not. These goals or intended learning outcomes (ILOs) should be assigned before teaching. Writing test questions is not a matter of writing questions that have answers inside the book; teachers should design their tests in a scientific process that tests students' achievement of ILOs, i.e. test questions must be aligned with ILOs.

Test results help teachers evaluate students' digestion of the course, so a test must be designed adequately. To make a questions bank for an English course, teachers should know the following:

1- Bloom Taxonomy (cognitive domain)

2- Types of questions

3- Table of specification

\section{BLOOM TAXONOMY}

Bloom B, S(1965) in his handbook Taxonomy of Educational Objectives ,displayed his “ Bloom's taxonomy” which he created in order to promote higher forms of thinking in education. He divides the cognitive domain to six levels of educational objectives:
1- Knowledge
2- Comprehension
3- Application
4- Analysis
5- Synthesis
6- Evaluation

Figure .1 bellow illustrates the old version of Bloom's cognitive domain. 


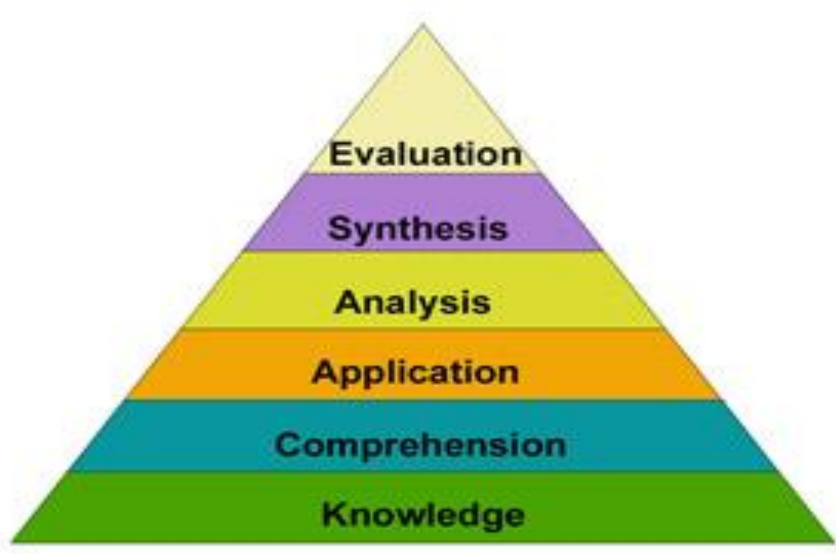

Source: http://cehdclass.gmu.edu/ndabbagh/Resources/IDKB/bloomstax.htm Figure. I: Old Version of Bloom' Cognitive Domain

Later in the mid-nineties, Lorin Anderson, a former student of Bloom, and David Krathwohl developed Bloom's Taxonomy (see Figures. II\& III for illustration) and made some changes as follows:

1- Changing names from noun to verb forms.

2- Rearranging the highest level as in figure. II below.

3- Creating a knowledge matrix process and levels see figure. III below.

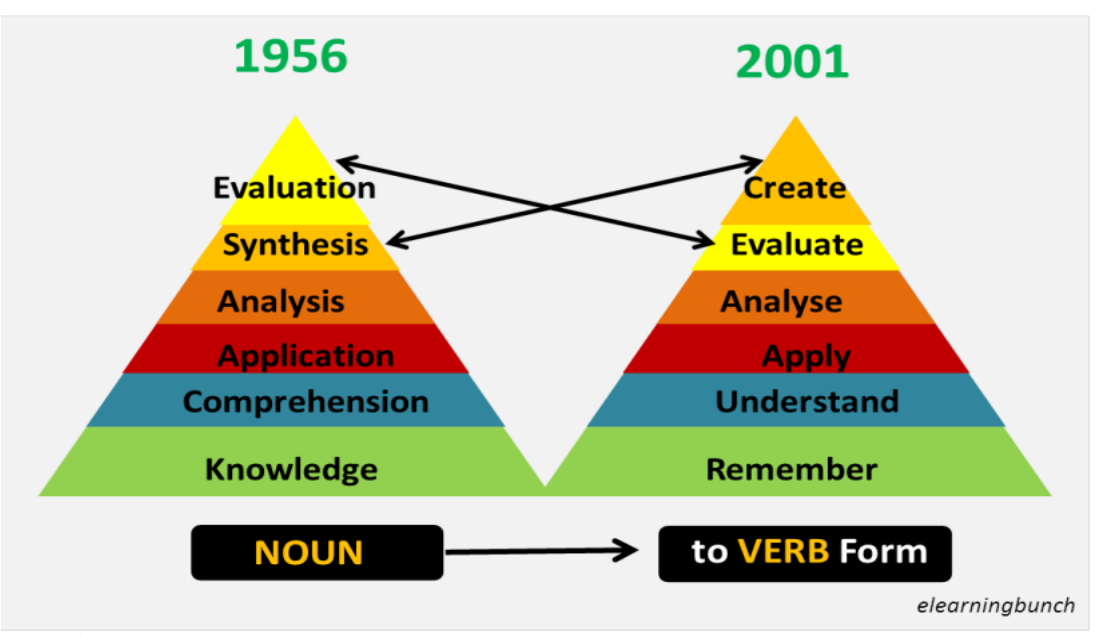

Source: https://elearningbunch.wordpress.com/2013/02/20/revised-bloom-taxonomy/ Figure. II: Revised Bloom's Taxonomy

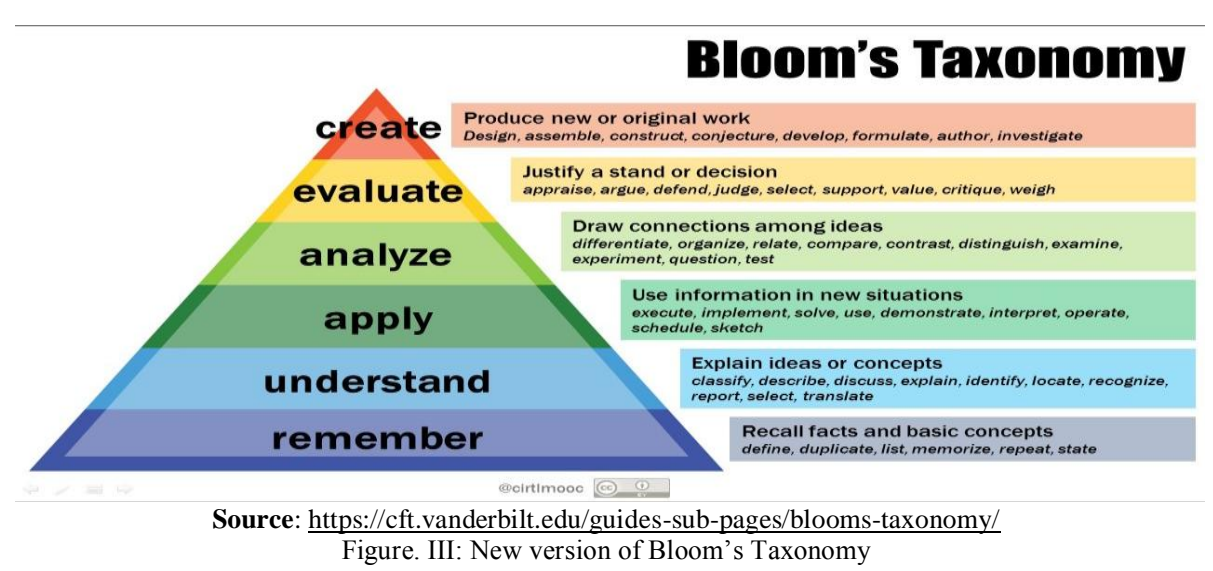

Teachers should consider what level of thinking in Bloom's Taxonomy they intend to achieve as a first step when they start planning their lessons. As a sequence they consider these levels which they have planned when they construct their tests' questions. It is very important to use the right stem verbs that test the ILOs. Table. I below illustrates lists of stem verbs that teachers can use to determine ILOs and write their test questions according to these levels. 
TABLE. I:

STEM VERBS OF THE BLOOM'S TAXONOMY LEVEL

\begin{tabular}{|c|c|c|}
\hline Bloom's Level & Stem Verbs (keywords ) & Example Learning Objective \\
\hline Create & $\begin{array}{l}\text { design, formulate, build, invent, create, compose, generate, } \\
\text { derive, modify, develop }\end{array}$ & $\begin{array}{l}\text { By the end of this lesson, the student will be able to design } \\
\text { an original homework problem dealing with the principle of } \\
\text { conservation of energy. }\end{array}$ \\
\hline Evaluate & $\begin{array}{l}\text { choose, support, relate, determine, defend, judge, grade, } \\
\text { compare, contrast, argue, justify, support, convince, select, } \\
\text { evaluate. }\end{array}$ & $\begin{array}{l}\text { By the end of this lesson, the student will be able to } \\
\text { determine whether using conservation of energy or } \\
\text { conservation of momentum would be more appropriate for } \\
\text { solving a dynamics problem. }\end{array}$ \\
\hline Analyze & $\begin{array}{l}\text { classify, break down, categorize, analyze, diagram, } \\
\text { illustrate, criticize, simplify, associate. }\end{array}$ & $\begin{array}{l}\text { By the end of this lesson, the student will be able } \\
\text { to differentiate between potential and kinetic energy. }\end{array}$ \\
\hline Apply & $\begin{array}{l}\text { calculate, predict, apply, solve, illustrate, use, demonstrate, } \\
\text { determine, model, perform, present. }\end{array}$ & $\begin{array}{l}\text { By the end of this lesson, the student will be able } \\
\text { to calculate the kinetic energy of a projectile }\end{array}$ \\
\hline Understand & $\begin{array}{l}\text { describe, explain, paraphrase, restate, give original } \\
\text { examples of, summarize, contrast, interpret, discuss. }\end{array}$ & $\begin{array}{l}\text { By the end of this lesson, the student will be able to describe } \\
\text { Newton's three laws of motion to in her/his own word. }\end{array}$ \\
\hline Remember & $\begin{array}{l}\text { list, recite, outline, define, name, match, quote, recall, } \\
\text { identify, label, recognize }\end{array}$ & $\begin{array}{l}\text { By the end of this lesson, the student will be able to recite } \\
\text { Newton's three laws of motion. }\end{array}$ \\
\hline
\end{tabular}

Using Bloom's Taxonomy in planning and constructing test questions helps to meet the quality matter standards of course teaching and achieve the course objectives (i.e. which are broad and cannot be measured without achieving lesson objectives, which are specific).

\section{TYPES OF TEST-QUESTIONS}

Before illustrating types of test questions, teachers should differentiate between types of tests. Some of these types are:

- A proficiency test, which measures the overall ability in a language the candidate possesses in general, such as in speaking and listening course.

- An achievement test, which tests students' knowledge of a content that has been taught on a certain course.

- A diagnostic test, which specifies strength and weakness that a learner may have in a specific area of a course or skill.

- A prognostic test, which draws a prediction of students' future performance in course.

Each of the above tests uses different types of questions: objective or subjective questions. Both type of these questions has pros and cons, which teachers should realize before writing their tests questions.

Test questions can be divided to two main types:

\section{A. Objective Questions}

Objective questions can be summarized in four types:
i. Multiple choice questions (MCQs)
ii. True/False questions
iii. Matching table
iv. Fill in the blank

\section{B. Subjective Questions}

Subjective questions can be summarized in two types:

i. Short answers questions

ii. Essay questions:
a- Guided writing questions
b- Open writing questions
c- Performance questions

The course and lesson objectives must be considered when writing test questions. Teachers should choose the best format that suits these objectives and ensures that students achieve ILOs.

\section{TABLE OF SPECIFICATION}

Table of specification or blueprint (TOS) is a two-way chart that helps teachers map a test onto their instructional objectives for a given segment of the course study. TOS identify which topics to be covered by a certain test, and it also gives a clear picture of the number of items and points associated to these items in a test of a certain topics. TOS benefits students and teachers, and can be used to help educators to:

1- Provide a link between teaching and testing.

2- Put instructional objectives of any part of course into a map for a test- questions.

3- Make test construction process clear. 
4- Achieve the validity of teacher-made testing.

5- Identify all area of content to be covered in the class before the test.

6- Identify which level of the cognitive domain of Blooms Taxonomy the questions of the test test .

\section{Steps of using TOS}

Al-Bashier, et al. (2009) state the steps of using TOS, as follow:

- Specify the educational objectives of the content which will be tested.

- Specify the items in the content to be assessed.

- Specify the percentages of the content division based on the following equation.

$$
\frac{\text { Hours of each unit }}{\text { Total hours of the course }} \times 100
$$

- Specify the level of the cognitive domain to be assessed according to the teaching specification. E.g. 25\% remembering, $30 \%$ understanding, $20 \%$ applying, $20 \%$ creating.

- Specify the number of questions for the test e.g. 20 questions, 40 questions, etc.

- Specify the number of items in each question.

To use the equation $\frac{\text { Hours of each unit }}{\text { Total hours of the course }} \times 100$ to find the percentage of content division based on a course specification

Table. II below illustrates analysis for a course specification of Applied Linguistics, as an example for content analysis as a first step for constructing test questions. It illustrates how to use the equation $\frac{\text { Hours of each unit }}{\text { Total hours of the course }} \times 100$, to find the percentage of content division based on a course specification

TABLE. II:

CONTENT ANALYSIS For A COURSE SPECIFICATION, APPLIED LINGUISTICS 2

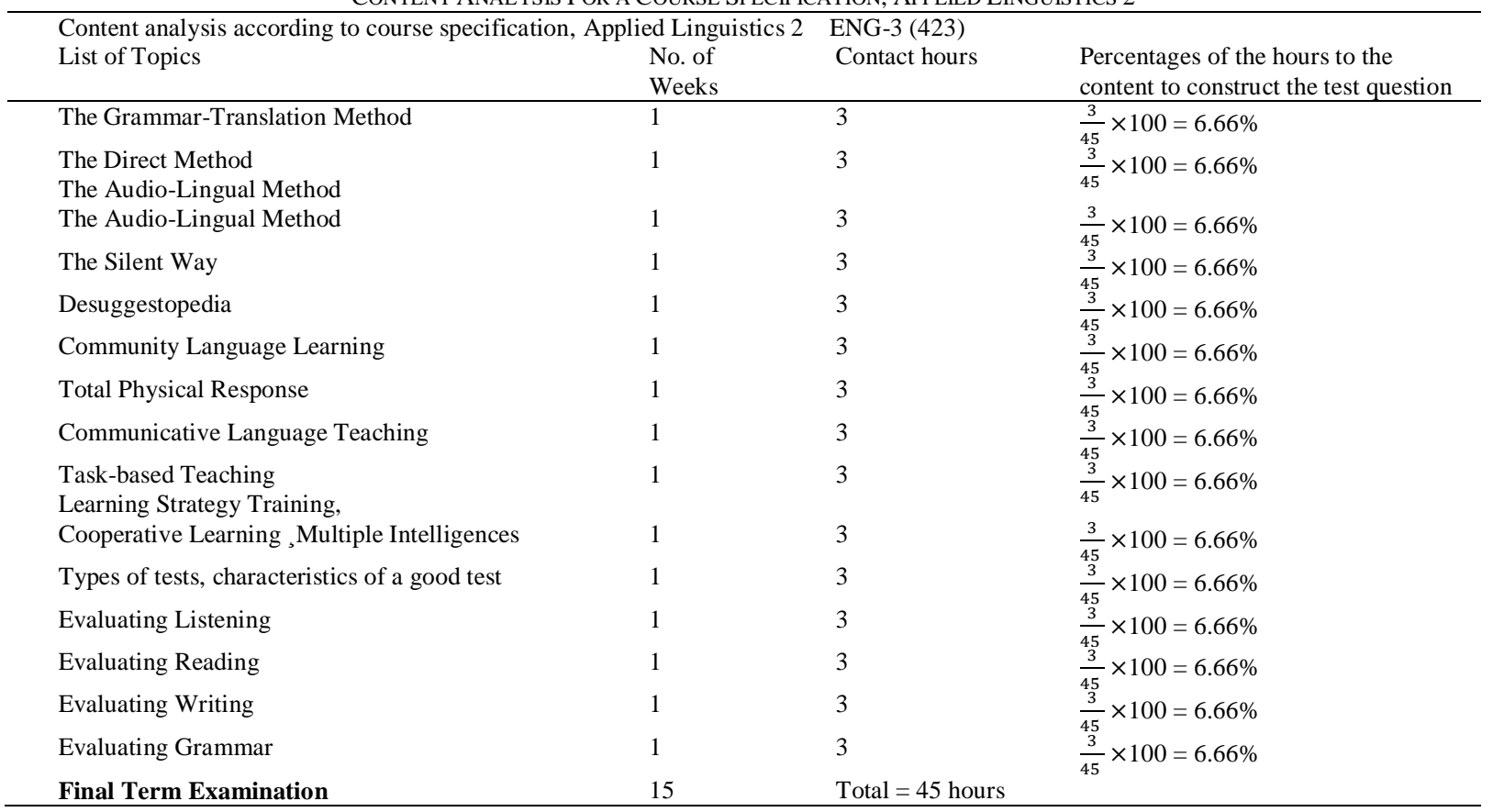

After determining the ratio of the content division (which shows the ratio of each part of the content questions to the total of the test-questions (6.6\% of the tests question of each topic if they are all covered), then teachers go on to the next step to decide the number of questions for each level of cognitive domain to assess covering each part of the course according to the division results. See Table. III 
TABLE. III:

EXAMPLE OF USING TOS TO CREATE QUESTIONS REFLECTING THE CONTENT AND LEARNING LEVEL ACCORDING TO COURSE OBJECTIVES

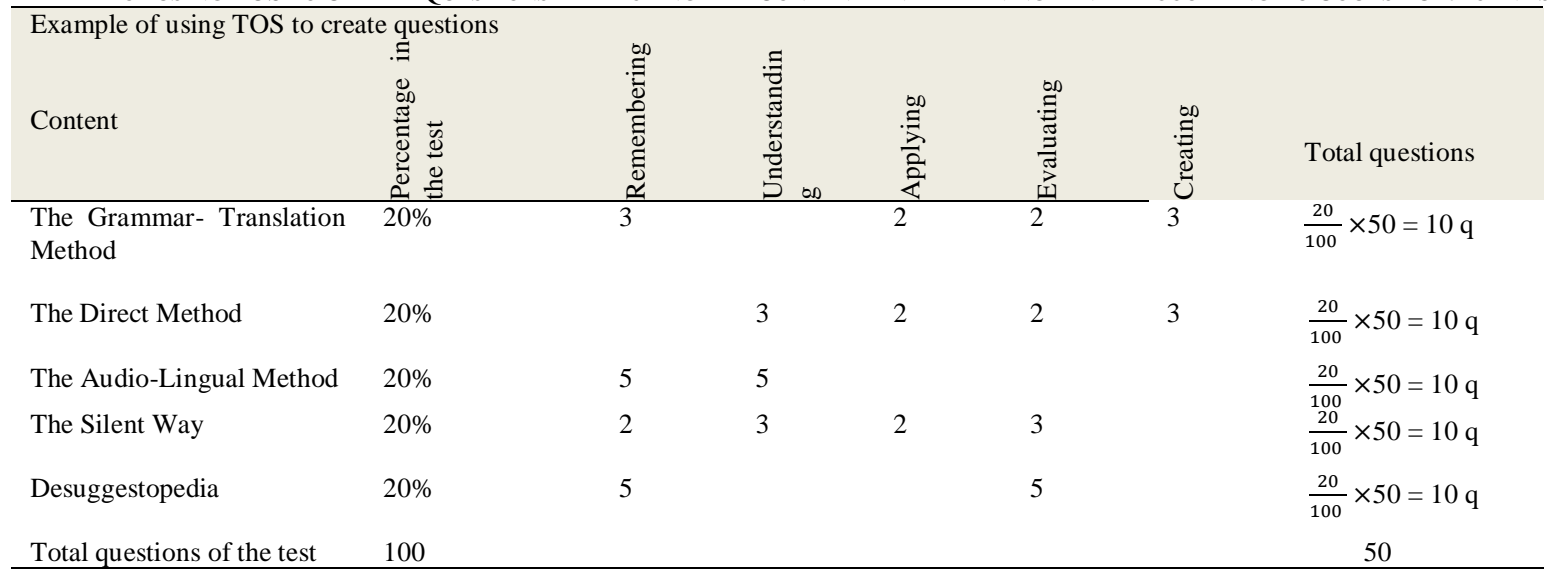

Table. III illustrates how the number of questions is divided on the course content according to the period of time determined in the course specification for each unit, and how TOS helps educators decide which levels of learning domains to test. Taking "connecting idea unit" as an example, 10 questions out of 50 questions will be on this area , these 10 questions will be designed to test certain level of leaning domain according to this unit objectives, such as : remembering 3 questions, applying 2 questions, evaluating 2 questions, and creating 3 questions, to have 10 questions in total that test the Grammar-Translation Method part. If we take the Audio-Lingual Method unit, there should be 10 questions, 5 questions test remembering, 5 questions test evaluating, and so on for the rest of the units using same equations on all units. After testing the students, teachers should find out the levels of difficulty of the test questions to decide whether to reuse test questions or develop them in the future. Specifying levels of difficulty helps teachers to map-picture about planned skills students have not achieved. Moreover, it helps teachers evaluate themselves and, finally, it helps teachers build the foundation needed to create a personal questions bank.

The levels of difficulty of any test-questions can be determined by testing a small sample of students, then marks obtained in this test for each question are analyzed using equation to put questions in categories.

\section{How to Evaluate Levels of Difficulty of Test Questions?}

After analyzing students' results, teachers can use the following equation to find the percentage that reflects the levels of difficulty.

Indictor of level of difficulty $=\quad \frac{\text { no. of correct answers }}{\text { total no.of students }} \times 100$

Table. IV below illustrates percentage agreement of questions' levels of difficulty.

TABLE. IV:

PERCENTAGE AGREEMENTS OF QUESTIONS' LEVELS OF DIFFICULTY

\begin{tabular}{l|l|l}
\hline Difficult & Ideal & Easy \\
\hline Less than $50 \%$ & $50 \%$ & More than $50 \%$ \\
\hline
\end{tabular}

Taking the ratio from the table above as a classifier map, if the total number of students sat for this test $=50$, and only 10 students answer question no.1. Difficulty level of this question can be calculated using the equation mentioned above as follow:

Difficulty level of the question $=\quad \frac{10}{50} \times 100=20 \%$

According to the ratio result indicator, this question is classified as a difficult question.

Table. V below illustrates questions' levels of difficulty according to the ratio after analyzing each question answer results of the test, using the equation $\frac{\text { no.of correct answers }}{\text { total no.of students }} \times 100$

TABLE. V

QUESTIONS' LEVELS OF DIFFICULTY ACCORDING TO PERCENTAGES

\begin{tabular}{lll}
\hline Question No. & Indicator of level of difficulty & Meaning \\
\hline 1 & $25 \%$ & Difficult \\
2 & $70 \%$ & Easy \\
3 & $60 \%$ & Easy \\
4 & $90 \%$ & Very easy \\
5 & $50 \%$ & Ideal \\
6 & $5 \%$ & Very difficult \\
\hline
\end{tabular}

Determining questions' level of difficulty helps teachers reuse their ready questions in future tests if they succeed to store these questions in a proper questions bank. 
After classifying the questions according to Bloom taxonomy, objectives and level of difficulty, it will be easy to prepare question bank by creating folders according to unit, with several folders inside each unit. If we take 'Applied Linguistics-2' course for example, we create a main folder named "Applied Linguistics". Inside this main folder, we create sub-folders according to the course units "number of units", and in each unit we create another six sub-folders, each of which should be for one level of the cognitive domain. Then, inside each level of the cognitive domain, we insert two folders, one for the objective questions and one for the subjective questions. Inside the objective questions folder, we create four folders: multiple choice questions (MCQs), matching questions, true/false questions and fill-inthe-blank questions. Inside the subjective questions folder, we insert three folders, one for short answer questions, the second for essay-type questions, and the third for performance test/oral questions. Inside the essay questions folder, we insert two folders, one for guided writing questions and the second for open writing questions.

Making question banks is a matter of organizing folders according to a scientific process using Bloom Taxonomy Cognitive Domain. Then, test questions are written using TOS, which makes testing easier for the teacher to feed the questions bank and later take out questions to make their tests according to the unit objectives, type of questions and learning level of the cognitive domain. All these aspects boast the quality of teachers' questions bank in terms of validity and reliability and help to fulfill the desired learning outcomes of the course.

Going on with using the questions bank, teachers later can start making folders for levels of difficulty after calculating test results. After result analysis, question results can be classified according to the statistical process equation (which has been explained in Table (5) and Table IV.

Questions can be moved from folder to folder inside the questions bank levels of difficulty folders, which are the only folders that cannot be fed until teachers analyze tests results. Designing a personal questions bank is not an easy task. It is hard and hectic at the beginning, but its results are fruitful and satisfying for teachers in the end. For a sample of questions bank design, Figure IV below illustrates a sample of a course folder "Applied Linguistics 2", showing how to start a questions bank, and how to arrange files/folders inside a main course questions bank folder.

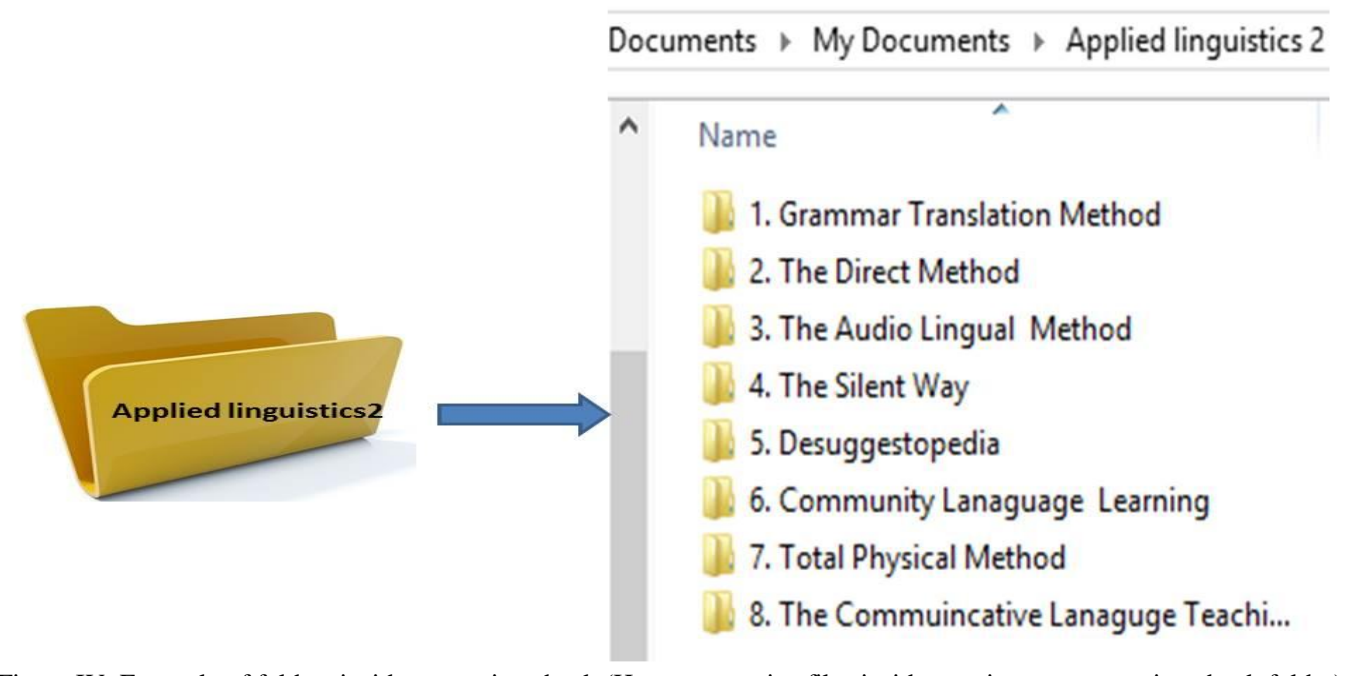

Figure IV: Example of folders inside a questions bank (How to organize files inside a main course questions bank folder)

Figure V below illustrates folder division according to Bloom's Taxonomy. For each chapter, there are several folders, each of which for questions that covers one level of Bloom's Taxonomy. Each folder is fed by questions that examine that specific level of Bloom's Taxonomy of that course chapter.

\section{1- Remembering \\ 2- Understanding \\ 3- Applying \\ 4- Analyazing \\ 5- Evaluating \\ 6- Creating}

Figure V: Examples of folders inside a course chapter, illustrating folder division according to Bloom's Taxonomy

For each level of Bloom's Taxonomy, there are two types of questions, objective questions and subjective questions. A folder is created for each type of questions, whether objective or subjective. For each type of questions, several 
folders are opened, such as true/false questions, Multiple-choice questions, matching questions, and fill-in-the-blanks questions. These folders are fed by questions from the specific chapter. Later, after students take the test, the teacher calculates the levels of difficulty, and moves questions inside folders accordingly. In each type of questions, there are levels of difficulty. This is a continuous process done after each test result analysis: questions are moved between folders according to the levels of difficulty. See Figure. VI below for illustration.

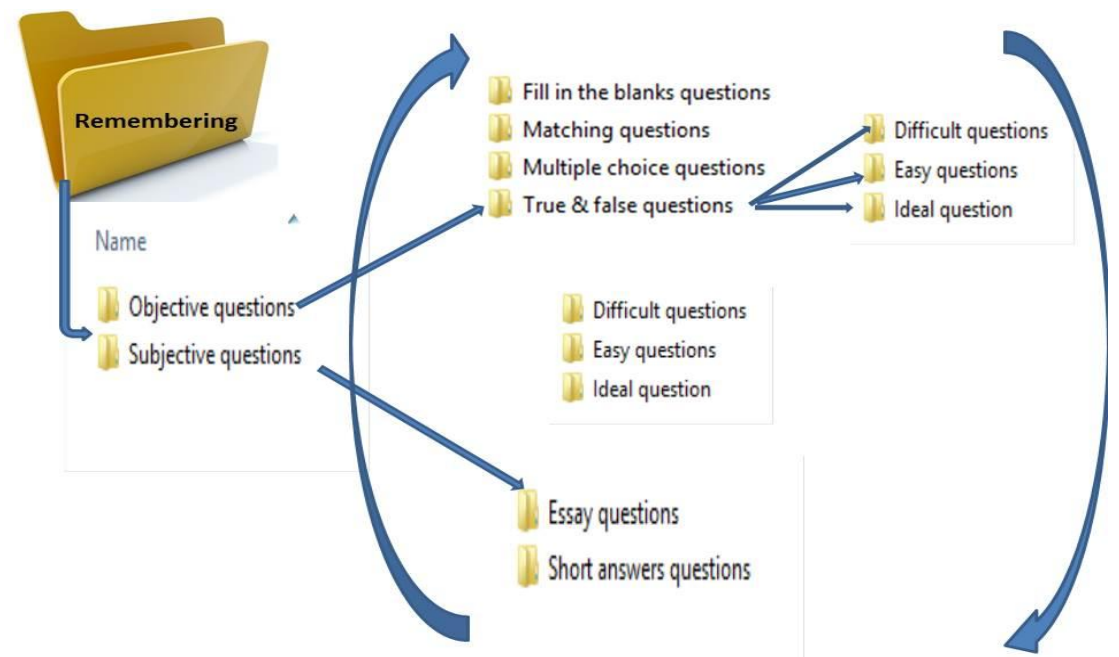

Figure VI: Illustration of folders inside a level of cognitive domain, showing folders of different types of question types

\section{USING QUESTIONS BANK IN E-LEARNING}

No one can deny that e-leaning has become a dominant method used in education. Exams and tests are used for assessment whether the program is taught online or in traditional class. Questions bank helps educators in designing tests and exams in both situations. Moreover, it can help to minimize cheating between students if the test is electronic. Designing an online course is not an easy task but having a personal questions bank can help to make this task easier. Knowing how to make questions bank, and how to sort question inside it helps educators who teach online to make their test in a convenient and easy way.

Modern institutions use a specific programs or systems for online learning such as Blackboard. Taking Blackboard as an example, Blackboard has a pool for questions for each course, we can sort out questions according to Figure VI in our computer Then we can feed the course pool with the questions divided in folders according to Bloom Taxonomy (level, types and difficulty). If we succeed to feed the pool with the questions divided in a right way, then it will be easy to construct an online exam that is valid and reliable. Add to that the time we spend in preparing a test every time. Educators can make random block of questions for a certain course test, after choosing the desired type of questions that are divided in folders inside that course pool. We can specify the number of questions, type of question and level of difficulty, and the system will choose the questions randomly from the folders in the pool with the desired criteria. Beside that there is a great advantage that each student will have different questions, and if they have multiple attempts, they will have different questions each time.

If we compare this method of testing, which depends completely on questions bank in pools, with regular tests made in need in at a certain time with a fixed number of questions, we will find many advantages and flexibility.

Using questions bank will help to decrease cheating and will reflect a real picture of the learning process, it will give a picture: a. whether the course has achieved its learning outcomes and objectives or not. b. whether the test was valid and reliable or not. All this can be clear from students' achieved mark in a certain test.

Knowing the right steps for making a questions bank will help educators to overcome difficulties that may face them in different circumstances, and will help them make use of technological development, more over to that, they can make use of the advantages provided in online systems or programs.

\section{CONCLUSION}

Question banks constitute a very useful and handy tool for teachers to assess their students, achieve pre-determined ILOs, and ensure consistent and continuous improvement of their teaching methods and techniques. More particularly, designing questions bank helps teachers to:

1- Have tests that are not biased and cover all parts of the course.

2- Decrease stress associated with test preparation.

3- Develop tests that suit their students' personalities with various features, such as easy and difficult. 
4- Decrease risk of unexpected circumstances that may happen to teachers in test time, such as getting sick or having any accidental issues: test questions can be selected easily with less efforts.

5- Share questions with colleagues who are teaching the same course.

6- Have alternative tests when there is a leaking accident.

7- Develop their test questions every year according to results analysis.

8- Make use of the advantages that are provided in E-leaning programs and systems.

\section{REFERENCES}

[1] Al-Bashier M., Abderahaman N. \& Altaib, A. (2009). Guidebook of Achievement Test Preparation. Khartoum: Aro. Co.. p. $52-59$.

[2] “Bloom's Taxonomy”, retrieved from https://cft.vanderbilt.edu/guides-sub-pages/blooms-taxonomy/ accessed 29/3/2020).

[3] "Bloom's Taxonomy of Cognitive Development", retrieved http://cehdclass.gmu.edu/ndabbagh/Resources/IDKB/bloomstax.htm accessed 29/3/2020).

[4] Bloom B, S. (1965). Taxonomy of Educational objectives, Handbook1, The cognitive Domain. New York : David Mckay Co. Inc

[5] "Bloom's Taxonomy of Learning Domains", retrieved from: http://www.nwlink.com/ donclark/hrd/bloom.html accessed 29/3/2020).

[6] Bloom B. S. (1956). Taxonomy of Educational Objectives, Handbook 1: The Cognitive Domain. New York: David Mackay Co. Inc. pp. $29-18$.

[7] Brown, H. Douglas (2004). Language Assessment: Principles and Classroom Practices. London: Longman.

[8] British Council, "Test Question Types", retrieved from: https://www.teachingenglish.org.uk/article/test-question-types accessed 29/3/2020).

[9] Fry, H., Ketteridge .S \& Marshall S. (2009). A Handbook for Teaching and Learning in Higher Education Enhancing Academic Practice, 3rd edition. New York and London: Routledge Taylor and Francis. pp. 44-46,

[10] James, W. (2003). "Test better, Teach Better: The instructional role of assessment”, retrieved from http://www.ascd.org/publications/books/102088.aspx accessed 29/3/2020).

[11] "Linking learning outcomes to assessment: Bloom's Taxonomy", retrieved from: https://linkinglearningoutcomestoassessments.wordpress.com/bloomstaxonomy/ accessed 29/3/2020) Teaching.aspx accessed $29 / 3 / 2020)$

$$
\text { Learning Outcomes to Assessment”, }
$$$$
\text { retrieved }
$$

from: https://linkinglearningoutcomestoassessments.wordpress.com/bloomstaxonomy/ accessed 29/3/2020).

[13] "Questions Types", retrieved from: https://support.schoology.com/hc/en-us/articles/205271688-Test-Quiz-Question-Types accessed 29/3/2020)

[14] "Revised Bloom's Taxonomy", retrieved from: https://elearningbunch.wordpress.com/2013/02/20/revised-bloom-taxonomy/ accessed 29/3/2020).

[15] Shabatura, J. "Using Bloom's Taxonomy to Write Effective Learning Objectives", retrieved from: https://tips.uark.edu/usingblooms-taxonomy/ accessed 29/3/2020).

[16] "Table of Specifications", University of Kansas, retrieved http://www.specialconnections.ku.edu/?q=assessment/quality_test_construction/teacher_tools/table_of_specifications accessed 29/3/2020).

[17] Tracy. J. (2015). "Objective or Subjective? Those are the Questions", retrieved from: https://www2.palomar.edu/pages/testwritingstrategies/2015/04/13/objective-or-subjective-those-are-the-questions accessed $29 / 3 / 2020$ )

[18] “Using Bloom's Taxonomy to Write Effective Learning Objectives", retrieved from: https://tips.uark.edu/using-bloomstaxonomy/ (accessed 29/3/2020).

Mona M. Hamad is a Sudanese, her Ph.D. in Education "Curriculum \& Teaching Methods of English Language" from AlZaiemAzhhri University, Khartoum, Sudan. She obtained her master's degree in Education Technology (2005) from AlZaiemAzhhri University, Khartoum, Sudan. She also obtained a higher degree Diploma in ELT (2001) from Khartoum University, Khartoum, Sudan. Her Bachelor of Arts (1991) was obtained from AL-Neelain University, Khartoum, Sudan.

She has been working as Assistant Professor at King Khalid University, Muhayil, English Department since 2012. She has worked as Part-time Assistant Professor for Al-ZaiemAzhhri University, Sudan, Khartoum from 2010-2012; she also worked as English language teacher for Secondary level for the Ministry of General Education, Sudan, Khartoum from 1996-2012 .

She published many papers and two books. Dr. Mona M. Hamad is a member of KSAALT /TESOL (Kingdom of Saudi Arabia Association of English Language Teachers) \& ASTEL (Association of Sudanese Teachers of English Language). 


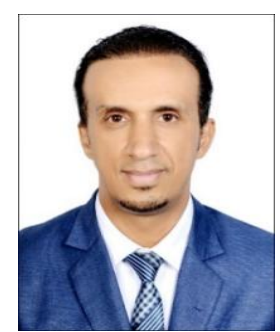

Ehab Alnuzaili was born in Ibb Town (Yemen) in 1981. While he received his BA in English from Ibb University (Yemen), he pursued his $\mathrm{MA}$ and $\mathrm{PhD}$ at the Centre for Applied Linguistics and Translation Studies of the University of Hyderabad (Hyderabad, India). Specialized in applied linguistics, he obtained his MA in 2011 and $\mathrm{PhD}$ in 2013.

He is now an Assistant Professor at the College of Science and Arts (Muhayil Aseer), King Khalid University (KSA). Earlier, he worked for about a decade at the National Institute for Administrative Science (Ibb, Yemen). The main research areas of interest include ELT, applied linguistics, translation studies, teaching Arabic for foreign learners, and English for nonnative speakers.

Dr. Alnuzaili is an active member of the organizing committee of Tehama Annual Scientific Conference. His hobbies include director assistant of College registration and technician for global football. 